\title{
Direct introduction of cloned DNA into the sea urchin zygote nucleus,
} and fate of injected DNA

\author{
ROBERTA R. FRANKS, BARBARA R. HOUGH-EVANS, ROY J. BRITTEN \\ and ERIC H. DAVIDSON \\ Division of Biology, Califomia Institute of Technology, Pasadena, CA 91125, USA
}

\section{Summary}

A method is described for microinjection of cloned DNA into the zygote nucleus of Lytechinus variegatus. Eggs of this species are unusually transparent, facilitating visual monitoring of the injection process. The initial fate of injected DNA fragments appears similar to that observed earlier for exogenous DNA injected into unfertilized egg cytoplasm. Thus after end-to-end ligation, it is replicated after a lag of several hours to an extent indicating that it probably participates in most of the later rounds of DNA synthesis undergone by the host cell genomes during cleavage. The different consequences of nuclear versus cytoplasmic injection are evident at advanced larval stages. Larvae descendant from eggs in which exogenous DNA was injected into the nuclei are four times more likely (32\% versus $8 \%$ ) to retain this DNA in cell lineages that replicate very extensively during larval growth, i.e. the lineages contributing to the imaginal rudiment, and thus to display greatly enhanced contents of the exogenous DNA. Similarly, $36 \%$ of postmetamorphic juveniles from a nuclear injection sample retained the exogenous DNA sequences, compared to $12 \%$ of juveniles from a cytoplasmic injection sample. However, the number of copies of the exogenous DNA sequences retained per average genome in postmetamorphic juveniles was usually less than $0 \cdot 1$ (range 0.05-50), and genome blot hybridizations indicate that these sequences are organized as integrated, randomly oriented, end-to-end molecular concatenates. It follows that only a small fraction of the cells of the average juvenile usually retains the exogenous sequences. Thus, even when introduced by nuclear microinjection, the stable incorporation of exogenous DNA in the embryo occurs in a mosaic fashion, although in many recipients the DNA enters a wider range of cell lineages than is typical after cytoplasmic injection. Nuclear injection would probably be the route of choice for studies of exogenous DNA function in the postembryonic larval rudiment.

Key words: microinjection, zygote nucleus, mosaic incorporation, sea urchin, DNA, Lytechinus variegatus, CyIIIa, cytoskeletal actin.

\section{Introduction}

Since the introduction of a method for microinjection of cloned DNA fragments into sea urchin egg cytoplasm (McMahon et al. 1984, 1985; Flytzanis et al. 1985), many different exogenous genes have been shown to undergo appropriate developmental expression in embryos developing from the injected eggs. These include histone genes (Colin et al. 1987); the $C y I I I a, C y I$, and $M$ actin genes of Strongylocentrotus purpuratus (Flytzanis et al. 1987; Katula et al. 1987; Hough-Evans et al. 1987; D. Livant \& E. Davidson, unpublished data); and the Specl gene (W. Klein, personal communication), and the SM50 spicule matrix protein gene of this species (H. Sucov, B. Hough-Evans \& E. Davidson, unpublished data). Cytoplasmic injection is easy, rapid, and obviously very useful for studies of gene regulation in the sea urchin embryo. However, a feature of this experimental approach, which for certain applications might constitute a significant drawback, is that incorporation into the embryo nuclei is usually mosaic (Flytzanis et al. 1985; Hough-Evans et al. 1987; unpublished DNA in situ hybridization data). The 
fraction of nuclei that retain the exogenous DNA after injection into unfertilized egg cytoplasm varies from a few per late cleavage embryo to a large proportion, and in the very exceptional case, all. In any given batch of embryos, however, only a minor fraction of the total embryonic cells contain the exogenous genes. Thus, it may be difficult to detect the effects of such genes on the host embryo, e.g. in the case where competition for regulatory factors would be expected to affect transcription of the homologous endogenous gene (Flytzanis et al. 1987). A more serious consequence of mosaic DNA incorporation is that, unless the exogenous DNA happens to be stably included in those cell lineages that give rise to the imaginal rudiment from which the juvenile sea urchin derives, the injected genes cannot be used to study rudiment development, and they will be lost at metamorphosis when the lineage elements confined to the larval structures are discarded. Thus Flytzanis et al. (1985) found that in cytoplasmically injected $S$. purpuratus eggs about $55 \%$ of the experimental embryos stably incorporated the DNA; but, of these, only $20 \%$ apparently included it in the growing imaginal structures, as indicated by its continuing replication beyond $\sim 500 \times$ the initial mass injected; and only $5-15 \%$ of juveniles emerging from metamorphosis in the samples studied retained exogenous DNA sequences.

In this paper, we compare the consequences of direct injection of exogenous DNA into the zygote nucleus to those of cytoplasmic injection, using the same cloned DNA construct and the same batches of $L$. variegatus eggs. We are here concerned with the fate of the injected DNA, rather than its expression, on which we have reported separately (Franks et al. 1988). While direct nuclear introduction does not convert stable embryonic incorporation of the DNA to a uniform rather than a mosaic process, the DNA is clearly more widely distributed amongst diverse embryonic cell lineages. Thus we show that nuclear introduction results in significant enhancement of the probability that the larval rudiment and the postmetamorphic juvenile sea urchin will include the exogenous DNA sequences.

\section{Materials and methods}

Preparation and injection of Lytechinus variegatus eggs

All operations were performed at room temperature. Gametes were obtained from Lytechinus variegatus (Marine Specimens Unlimited, Big Pine Key, FL) by intracoelomic injection of a $0.5 \mathrm{M}-\mathrm{KCl}$ solution. Eggs were prepared for microinjection as previously described (McMahon et al. 1985), except that the jelly coats were removed by exposure to Millipore filtered sea water (FSW) at a pH of $\sim 4.8$ for
2-4 min. Microinjection was carried out as described by McMahon et al. (1985), but with the following modifications. Microinjection needles were pulled on a P-77-B Brown-Flaming micropipette puller and broken off to form a tip 0.4-0.9 $\mu \mathrm{m}$ in diameter. For introduction of DNA into the zygote nucleus, the eggs were fertilized following fixation to protamine sulphate-coated microinjection dishes in FSW contanning penicillin at $20 \mathrm{i} . \mathrm{u} . \mathrm{I}^{-1}$ and streptomycin at $50 \mu \mathrm{gl}^{-1}$ (PSFSW) by addition of a few drops of dilute $(1 / 100)$ sperm, and the PSFSW was replaced by fresh PSFSW to remove excess sperm prior to microinjection. Following pronuclear fusion (about $20 \mathrm{~min}$ postfertilization) approximately $2 \mathrm{pl}$ of a $40 \%$ glycerol solution containing either 3000 or 7000 CyIIIa. CAT DNA molecules (Flytzanis et al. 1985, 1987) were injected into each egg. The plasmid had been linearized by digestion at the unique $S p h \mathrm{I}$ site. Because a continuously flowing microinjection needle was necessary for egg penetration (see McMahon et al. 1985), it was not possible to inject into the nucleus without introducing some DNA into the egg cytoplasm as well. The fraction of the total solution that was injected directly into the nucleus was not determined. An average of 50 zygote nuclei (out of a total of 80 fertilized eggs per dish) could be successfully injected in a $20 \mathrm{~min}$ interval. For cytoplasmic injections, 150 eggs per dish were injected over an interval of about $10 \mathrm{~min}$. Following microinjection, the embryos were allowed to develop in situ as described by McMahon et al. (1985).

\section{Culture of $\mathbf{L}$. variegatus larvae through metamorphosis}

Larvae were cultured as previously described (Flytzanis $e t$ al. 1985) for $S$. purpuratus with some modifications (Hinegardner \& Rocha Tuzzi, 1981; Leahy, 1986). At $48 \mathrm{~h}$ postfertilization, the plutei were transferred to either $125 \mathrm{ml}$ flasks ( $\sim 20 \mathrm{plutei} /$ flask) or $250 \mathrm{ml}$ flasks ( $\sim 40$ plutei/flask) containing FSW. The larvae were cultured at room temperature and fed about 3000 Rhodomonus sp. per litre daily beginning at $48 \mathrm{~h}$. At $2-3$ weeks, the mature larvae were transferred to glass Petri dishes $(15 \times 2 \cdot 2 \mathrm{~cm})$, the surfaces of which were coated with a bacterial film prepared as described by Cameron \& Hinegardner (1974). Metamorphosis occurred within $1 \mathrm{~h}$ and was taken to completion in $\sim 5$ days. The juvenile sea urchıns were then transferred to plastic dishes $(15 \times 1.5 \mathrm{~cm})$ that had a layer of surfacedwelling diatoms (Nitschia) growing on the bottom. The sea urchins were fed on diatoms for $\sim 2$ weeks, during which time they were transferred to fresh dishes every 2 days. They were subsequently placed in aquaria containing small alga-covered rocks on which they grazed, and $\sim 1$ week later the 'sea lettuce' Ulva was introduced for feeding.

\section{Determination of cell number during embryogenesis}

L. variegatus embryos were grown at $23^{\circ} \mathrm{C}$ and were collected at $1 \mathrm{~h}$ intervals. Cell numbers of $1-5 \mathrm{~h}$ embryos were counted directly from squashed preparations. Cell number in 4-12 $\mathrm{h}$-old embryos was determined from the amount of DNA measured in a known number of pooled embryos, on the basis that each diploid cell contains $1.6 \mathrm{pg}$ DNA (Pikó et al. 1967). Embryos were collected, spun down in a microfuge and resuspended in $50 \mu \mathrm{l} 250 \mathrm{~mm}$ - 
Tris- $\mathrm{HCl}, \mathrm{pH} 7 \cdot 8$. An equal volume of $1 \%$ Triton $\mathrm{X}-100$, $10 \mu 10.5 \mathrm{M}$-EDTA, pH $8 \cdot 0$, and $1 \mu 120 \mathrm{mg} \mathrm{ml}^{-1}$ proteinase $\mathrm{K}$ were added and the samples incubated for $2 \mathrm{~h}$ at $55^{\circ} \mathrm{C}$. DNA measurements were made fluorometrically using the DAPI (4,6-diamidino-2-phenlindole) method described by Brunk et al. (1979).

\section{Measurement of CAT DNA content per embryo}

The number of Cyllia.CAT molecules per embryo was determined essentially as described earlier (Flytzanis $e t$ al. 1987). Pellets containing 25-50 injected embryos were lysed in $100 \mu \mathrm{l}$ of $250 \mathrm{~mm}$-Tris- $\mathrm{HCl}, \mathrm{pH} 7 \cdot 8$, by three consecutive freeze-thaw cycles. Half of each lysate was removed for DNA measurement, mixed with an equal volume of $0 \cdot 1 \mathrm{M}$ EDTA, pH 8.0, $1 \% \mathrm{SDS}$, and incubated with $20 \mu \mathrm{g}$ of proteinase $\mathrm{K}$ for $2 \mathrm{~h}$ at $55^{\circ} \mathrm{C}$. The nucleic acids were extracted once in phenol:chloroform: isoamylalcohol (25:24:1) and once in chloroform: isoamylalcohol (24:1). A sample was used to determine the total amount of DNA recovered by the DAPI method and the remaining solution was treated with $0.4 \mathrm{M}-\mathrm{NaOH}$ at $65^{\circ} \mathrm{C}$ for $1 \mathrm{~h}$ to denature the DNA and hydrolyse the RNA, and was filtered onto nitrocellulose using a Schleicher and Schuell Minifold II slot-blot apparatus. The slots were cut in half, and the halves were separately hybridized with single-stranded RNA probes prepared from Sp6 vectors and containing sequences representing either the CAT gene or the singlecopy $S$. purpuratus $C y I$ actin gene sequence (Flytzanis $e t$ al. 1987; Lee et al. 1984). Probe specific activities were about $1.3 \times 10^{9} \mathrm{cts} \mathrm{min}^{-1} \mu \mathrm{g}^{-1}$. The reaction of the CyI probe with the measured mass of $S$. purpuratus carrier embryo DNA present in each half slot served as a hybridization efficiency standard. Hybridizations were carried out as described (Flytzanis et al. 1985, 1987), except that hybridizations with the CAT probe and CyI actin probe were at $40^{\circ} \mathrm{C}$ and $35^{\circ} \mathrm{C}$, respectively. The filters were washed twice with $2 \times \mathrm{SSC}$ $(0.15 \mathrm{M}-\mathrm{NaCl}, 0.015 \mathrm{M}$-sodium citrate $), 0.2 \% \mathrm{SDS}$ at room temperature, twice with $2 \times \mathrm{SSC}, 0.2 \% \mathrm{SDS}$ at $60^{\circ} \mathrm{C}$, and twice with $1 \times \mathrm{SSC}, 0.2 \% \mathrm{SDS}$ at $60^{\circ} \mathrm{C}$. Following autoradiography, each half-slot was cut out and counted, and calculations were carried out exactly as described earlier (Flytzanis et al. 1987).

\section{Measurement of CAT DNA content in 2- and 3-week L. variegatus larvae}

Total DNA was extracted from individual larvae derived from injected eggs and was analysed in dot blot assays as previously described (Flytzanis et al. 1985 ) using ${ }^{32} \mathrm{P}$ labelled pSVOCAT (Gorman et al. 1982), nick-translated to

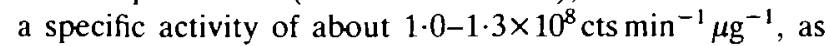
the hybridization probe. DNA standards containing $9.5 \times 10^{5}, 1.9 \times 10^{5}, 3.8 \times 10^{4}$ and $7.6 \times 10^{3}$ molecules of linearized CyIIIa. CAT were included on each filter. Autoradiography was performed with preflashed Kodak XAR-5 film using an intensifying screen at $-70^{\circ} \mathrm{C}$, and the approximate number of CyIIIa . CAT DNA molecules per larva was estimated by densitometry of the autoradiographs, with reference to the signals obtained with the known standards.

\section{Measurement of CAT DNA content in postmetamorphosis $\mathrm{L}$. variegatus juveniles}

Total DNA was extracted from individual sea urchins as described by Flytzanis et al. (1985). The DNA was dissolved in $40 \mu \mathrm{l} 10 \mathrm{~mm}$-Tris- $\mathrm{HCl}, \mathrm{pH} 8.0,1 \mathrm{~mm}$-EDTA, and onequarter of the sample was digested with $B g / I I$ and, after electrophoresis in a $\mathbf{0 . 8 \%}$ agarose gel, transferred to nitrocellulose (Southern, 1975) for hybridization with the nick-translated pSVOCAT probe. An aliquot of undigested DNA was included. Hybridizations and washes were carried out using the high criterion conditions of Lee $e t$ al. (1984). The number of CyIIIa.CAT DNA molecules per sample was estimated by densitometry with reference to standards, as above. The quantity of juvenile DNA present in the blots was obtained as follows. Subsequent to autoradiography, the hybridized counts were removed from the filters with two $15-20 \mathrm{~min}$ washes of $500 \mathrm{ml} 0.1 \times \mathrm{SSC}$, $0.1 \% \mathrm{SDS}$, at $95^{\circ} \mathrm{C}$. The filters were then rehybridized with the insert derived from pCyI (3') (Lee et al. 1984), which represents a single-copy CyI actin gene sequence from the genome of $S$. purpuratus, nick-translated to a specific activity of about $1 \cdot 0-1 \cdot 3 \times 10^{8} \mathrm{cts} \mathrm{min}^{-1} \mu \mathrm{g}^{-1}$. Under the low criterion hybridization conditions of Lee et al. (1984), this probe reacts clearly with a single-copy sequence of the $L$. variegarus genome. This reaction was used to estimate by densitometry the amount of total DNA transferred onto the nitrocellulose, by comparison to the hybridization reaction obtained with standard amounts of $L$. variegatus genomic DNA present on the same filters. The number of cells represented in each lane was then calculated on the basis that each diploid cell contains $1.6 \mathrm{pg}$ DNA (Pikó et al. 1967). Thus, the number of CAT DNA molecules per sample could be converted to average number of CAT molecules per cell.

\section{Results}

Microinjection of DNA into nuclei of fertilized eggs of Lytechinus variegatus

A method for microinjecting DNA into the cytoplasm of unfertilized eggs of the sea urchin Strongylocentrotus purpuratus was previously developed in this laboratory, as described by McMahon et al. (1985). The opaque eggs of this species are not suitable for nuclear injection, however, and for this purpose we have turned to the almost transparent eggs of the Gulf Coast sea urchin Lytechinus variegatus, in which the zygote nuclei are clearly visible. The eggs are attached to plastic dishes by electrostatic attraction and prepared for microinjection with the minor modifications of our earlier procedure noted in Materials and methods. Initial attempts to microinject the unfertilized egg pronucleus failed because this organelle offers no resistance to the tip of the needle, which as it is advanced pushes the pronucleus away and across the egg. However, following fertilization and pronuclear fusion, a cytoskeletal architecture rapidly assembles (reviewed by Schatten, 1982) and 
the zygote nucleus becomes more stably anchored in its central position. As shown in Fig. 1, the zygote nucleus can now be penetrated by the microneedle, though it is important to stress that, since it is necessary to use a continuously flowing needle to gain penetration, DNA solution is distributed to the cytoplasm as well. With some practice, nuclear injection can be accomplished deftly, so that the dwell time of the needle within the egg approaches that required for cytoplasmic injection. The number of eggs that can be injected in the nucleus in a given amount of time falls within a modest factor of the number that can be injected in the cytoplasm in the same interval (see Materials and methods). An average of about $60-65 \%$ of $L$. variegatus embryos in nuclear injection samples and $75-80 \%$ of those in the cytoplasmic injection samples complete normal embryogenesis to the feeding pluteus stage, $48 \mathrm{~h}$ postfertilization. As described earlier for $S$. purpuratus (McMahon et al. 1985), there is some variability between batches of eggs in their response to microinjection and an occasional batch of injected eggs will arrest at a very early stage of development.

\section{Embryonic amplification of the exogenous DNA after} nuclear or cytoplasmic injection

The cloned DNA utilized for the present studies was the $S$. purpuratus CyIIIa - CAT construct described by Davidson et al. (1985) and Flytzanis et al. (1987). As indicated in the map reproduced in Fig. 2, this fusion construct includes several kilobases of upstream actin gene sequence, now known to contain regulatory elements that are necessary and sufficient to mediate

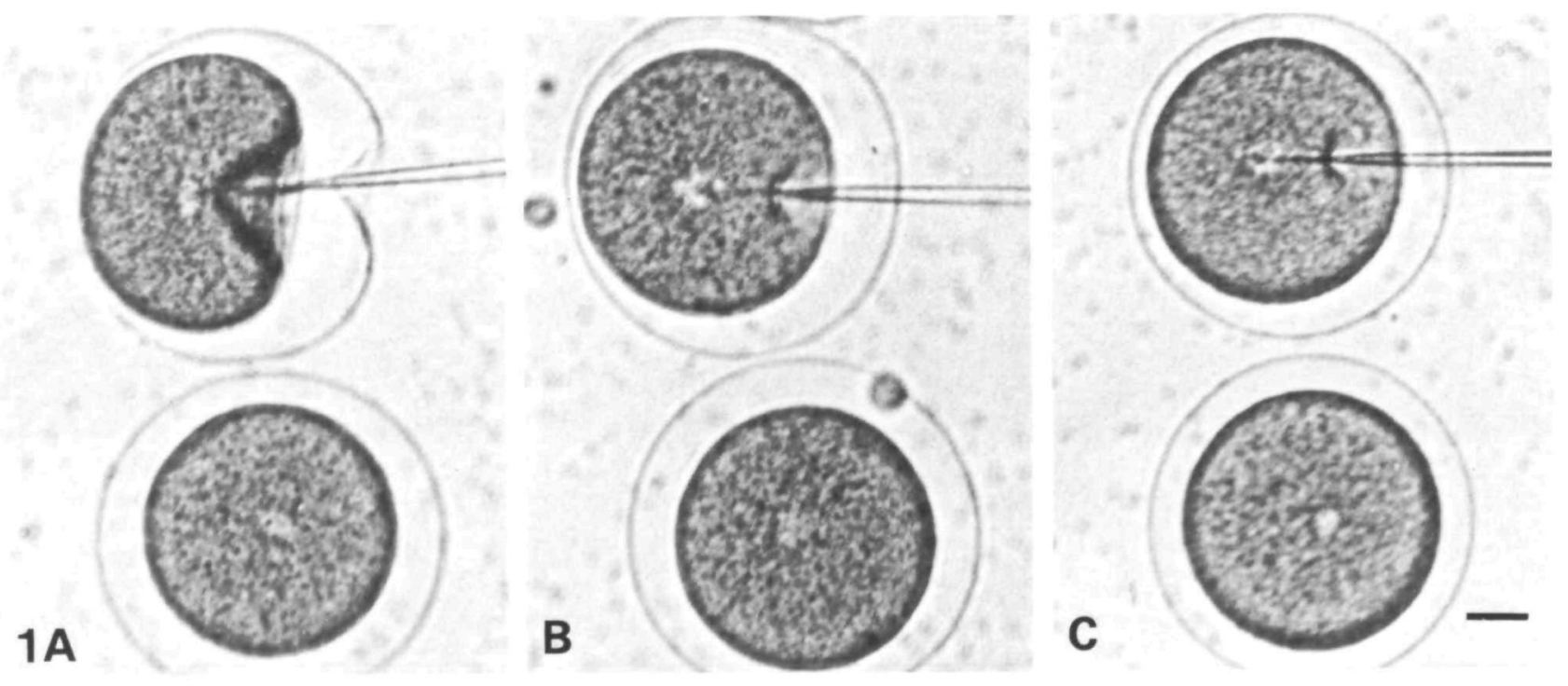

Fig. 1. Microinjection of $L$. variegatus zygote nuclei. Unfertilized eggs (120 $\mu \mathrm{m}$ diameter) were fixed to a tissue culture dish and fertilized as described in Materials and methods. Microinjections into zygote nuclei were performed following pronuclear fusion, about 15-20 min postfertilization, utilizing a continuously flowing needle. In A the injection needle can be seen just prior to penetration of the cell membrane. While the fertilization membrane is easily penetrated, the egg cell membrane, coated with hyalin, is often deeply indented before being pierced by the needle. In $\mathrm{B}$ and $\mathrm{C}$ both cytoplasmic and nuclear membranes have been penetrated by the needle tip, and DNA solution is in the process of being deposited in the nucleus.

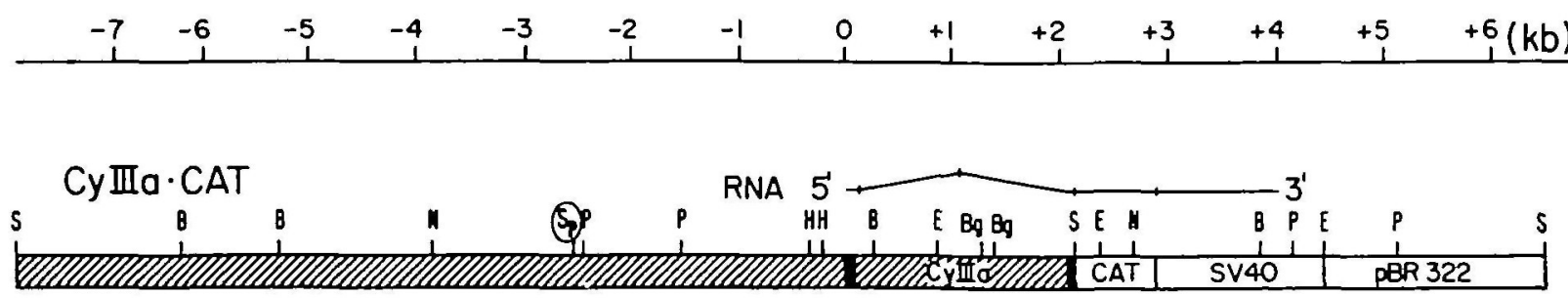

Fig. 2. Diagram of the CyIIIa.CAT fusion gene. Hatched areas represent sea urchin sequences, including a $2 \cdot 2 \mathrm{~kb}$ intron contained within the CyIIIa primary transcript (Akhurst et al. 1987). The fusion point is a SalI site located 11 codons following the start codon of the CyIIIa. CAT message (see Davidson et al. 1985; Flytzanis et al. 1987 for details of CyIIIa CAT construction). The CyIIIa - CAT construct also contains an SV40 poly(A) addition site and pBR322 plasmid sequences. The $S p h$ I site (circled) was used for linearization of the fusion gene for microinjection. Restriction sites shown are B, Bam HI; Bg, BglII; E, EcoRI; H, HindIII; N, NcoI; P, PstI; S, SalI; Sp, SphI. 
its correct spatial and temporal expression (Flytzanis et al. 1987; Hough-Evans et al. 1987). The CyIIIa regulatory region is ligated to a 'reporter' gene coding for bacterial chloramphenicol acetyl transferase (CAT). An SV40 poly(A) addition site and plasmid sequences are also included, and the total length of the construct is about $14 \mathrm{~kb}$.

The CyIIIa.CAT plasmid was linearized at a unique $S p h$ site about $2 \cdot 5 \mathrm{~kb}$ upstream of the transcription initiation site (Akhurst et al. 1987), and an average of 7000 molecules was introduced into the nucleus (plus cytoplasm) or exclusively into the cytoplasm of fertilized eggs. The embryos were then pooled at various developmental stages and their DNA was coextracted with a known number of uninjected $S$. purpuratus embryos. Slot-blot filter hybridization assays were carried out with a labelled RNA probe for the CAT gene sequence. A second probe consisting of a single-copy $C y l$ actin gene sequence present in the $S$. purpuratus genome (Lee et al. 1984) was used as a hybridization efficiency standard, as described in Materials and methods. A sample of a slot-blot hybridization set is reproduced in Fig. 3A. The radioactivity of the hybridized DNA was measured by scintillation counting of the filters and, after the efficiency correction, the average number of CyIIIa. CAT DNA molecules per injected embryo was estimated from the specific activity of the labelled CAT probe.

Quantities of CAT DNA per embryo are shown in Fig. 3B for two different matched nuclear and cytoplasmic injection series, each carried out with eggs from a single female. The exogenous DNA content was clearly amplified during cleavage of the host embryos, though to a different extent in the two batches of eggs utilized. Only small and possibly nonsignificant differences distinguish the curves representing CAT DNA content of embryos derived from eggs injected in the nucleus from those of the respective cytoplasmic injection controls. This result implies a high efficiency for the process by which DNA introduced into the cytoplasm is ultimately incorporated into the nuclei, presumably by assembly into nucleoid bodies which ultimately fuse with the blastomere nuclei (Forbes et al. 1983). That is, little additional replication is observed on direct introduction of the DNA into the nucleus, the only cellular compartment in which bulk DNA replication may occur.

The kinetics of exogenous DNA amplification shown in Fig. 3B are consistent with a mosaic incorporation mechanism for both nuclear and cytoplasmic injection samples. Our current evidence with respect to cytoplasmically injected $S$. purpuratus eggs suggests that stable incorporation of exogenous DNA typically occurs in one (or more) blastomere nuclei between 2 nd and 5 th cleavage, with a peak frequency at 4 th cleavage (B. R. Hough-Evans \& E. H. Davidson, unpublished data). Fig. 3B shows that by $9 \mathrm{~h}$ postfertilization (at $23^{\circ} \mathrm{C}$ ) most of the cells in normal L. variegatus embryos have undergone nine cleavages (i.e. except for the small micromeres, which arrest after 6th cleavage, and the cells of the skeletogenic mesenchyme, which enter a prolonged pause after 8 th cleavage; see Davidson, 1986 for review). In contrast to the cellular DNA, the exogenous DNA of experiment 1 of Fig. 3B has replicated only five times by the $10 \mathrm{~h}$ time point and, in experiment 2 , only three to four times. It should be noted, in reference to this comparison, that cleavage of injected eggs begins about 30 min- $1 \mathrm{~h}$ later than that of controls, apparently due to injection trauma. In experiment 1 , a lag of several cleavage cycles appears to ensue before the content of exogenous DNA in the majority of the injected embryos begins to amplify. It can be seen that thereafter, in this experiment, the relative rate of exogenous DNA increase is close to that of the cellular DNA. For the latter, between 2nd and 9th cleavage, the cellular DNA doubling time is about $0.9 \mathrm{~h}$ and, between 5 and $10 \mathrm{~h}$, it is about the same for both the nuclear and cytoplasmic injection samples of experiment 1 . The batch of eggs utilized for experiment 2 was evidently more heterogeneous as well as less active in exogenous DNA amplification. The average embryo of experiment 1 , whether belonging to the nuclear or the cytoplasmic injection sample, could thus have incorporated the exogenous DNA into a state where it could undergo cyclic replication in a single $3 \mathrm{rd}-4$ th cleavage blastomere in each embryo and subsequently replicated this DNA on about the same schedule as the endogenous nuclear DNA. Of course, on this evidence, it cannot be excluded that incorporation is actually more widespread early in development, but that there also occurs continuous loss of exogenous DNA sequence during cleavage. Fig. 3B indeed indicates a small, gradual decrease in exogenous DNA content after the blastula stage but, as shown below for these embryos and by McMahon et al. (1985) and Flytzanis et al. (1985) for $S$. purpuratus embryos, much of the exogenous DNA is permanently retained and continues to replicate for weeks during the growth of the feeding larva.

We may ask the nature of the limiting step that is responsible for the initial kinetics characterizing the onset of quantitative replication of the exogenous DNA. Since these kinetics appear the same in the cytoplasmic and nuclear injection samples, they are probably determined by an intranuclear process, possibly association of the exogenous DNA concatenate(s) with one or more of the blastomere chromosomes. We know from the clonal recovery study of 
Flytzanis et al. (1985) that the exogenous DNA is ultimately integrated into the genome, and this could occur within several cycles after incorporation (or insertion by microinjection) into the nuclear compartment, although there is yet no direct evidence for embryonic stages. In both the experiments shown in Fig. 3B, the average replication in the nuclear sample by the end of cleavage $(10 \mathrm{~h})$ in fact slightly exceeds that of the cytoplasmic injection sample, although this could merely result from experimental scatter. The following data show that, if it is real, this relatively modest difference $(\sim 30 \%)$ could be correlated with a higher probability of inclusion of the exogenous DNA in a wider range of cell lineages than in the cytoplasmic injection controls.

\section{Amplification of exogenous DNA in larvae derived from eggs injected in nucleus or cytoplasm}

Flytzanis et al. (1985) showed that following injection of linear DNA into the cytoplasm of unfertilized eggs of $S$. purpuratus the exogenous sequences persist stably in an average of $55 \%$ of mature larvae raised from the injected eggs. In subsequent studies higher fractions have often been observed. Measurements of the amounts of exogenous DNA present in these larvae indicated that, in about half of the individuals that retained these sequences, little or no further amplification occurred after embryogenesis, while in the remainder many additional rounds of exogenous DNA replication took place as the larvae developed. This phenonenon is almost certainly due to the mosaic confinement of the exogenous DNA to cell lineages that display relatively little postembryonic replication, e.g. the aboral ectoderm, in those larvae displaying no further amplification of exogenous DNA (Flytzanis et al. 1985). The larvae continuing to replicate their DNA would include, by the same argument, the exogenous DNA in lineages that are significantly augmented during postembryonic growth, i.e. mainly those descended from the embryonic vegetal plate, and also the small micromeres (Pehrson \& Cohen, 1986) and at least portions of the oral ectoderm (see Davidson, 1986 for review).

Fig. 4 shows that in $L$. variegatus direct introduction of exogenous DNA into the zygote nucleus in an appreciable number of recipients results in a large augmentation of the extent of its replication during larval growth. DNA was extracted from a set of 64 individual larvae, $2-3$ weeks after feeding began, that descended from eggs injected in the nuclei, and from

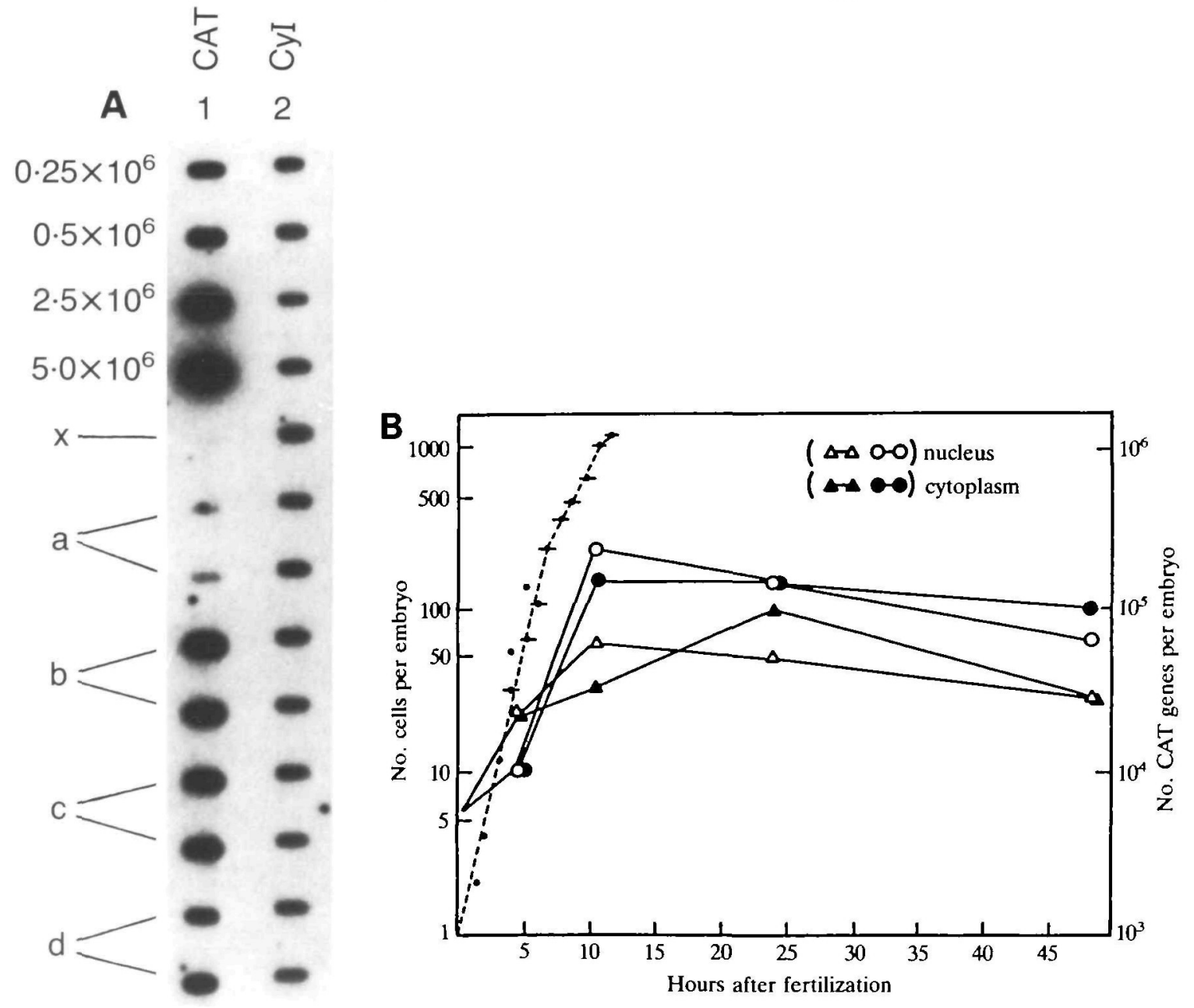


an equal number of larvae derived from cytoplasmically injected eggs. The individual DNA samples were then hybridized with a probe containing a portion of the CAT gene sequence, as illustrated in Fig. 4A. Dot-blot hybridizations such as these were utilized for estimations of the quantities of exogenous DNA in each larva (see legend). The large majority of positive larvae in both the nuclear and cytoplasmic groups contain amounts of CAT DNA greater than were generated on average during embryonic DNA replication. Thus, only $7 / 26$ larvae in the cytoplasmic

Fig. 3. Amplification of CyIIIa CAT DNA in nuclearand cytoplasmic-injected embryos. Fertilized eggs of $L$. variegatus were microinjected with about 7000 molecules of linearized CyIIIa. CAT plasmid DNA and allowed to develop at $23^{\circ} \mathrm{C}$. (A) Slot-blot assays of exogenous DNA amplification. Embryos were pooled at various times and their DNA was coextracted with a known number of $S$. purpuratus embryos and loaded onto a nitrocellulose filter. The top slot of each pair (a-d) contains the DNA of 25 embryos that had been injected in the zygote nucleus; the bottom slot of each pair contains the DNA of 25 cytoplasmically injected embryos. One half of each slot was hybridized with a ${ }^{32} \mathrm{P}$-labelled RNA probe representing the CyIIIa.CAT gene (column 1): slot a, 4-5 h; slot b, 10-11 h; slot c, 22-24h; slot d, 48h. Slot $x$ (column 1) represents the level of nonspecific binding of the CAT probe to the DNA extracted from uninjected embryos. The first four slots of column 1 contain standard quantities of linearized CyIIIa-CAT DNA. The second half of each slot was hybridized with a radioactive RNA probe whose sequence represents the single-copy CyI gene (Lee et al. 1984) of $S$. purpuratus (column 2). Each half slot in column 2 contains an amount of DNA equivalent to about $0.5 \times 10^{6} \mathrm{Cyl}$ actın DNA molecules. The region of the filter containing each half slot was excised and counted in a liquid scintillation counter. The number of CyIIIa.CAT DNA molecules present in each sample was calculated from the specific activity of the CAT probe and the hybridization efficiency, derived from the reaction of the CyI actin probe (see Materials and methods). (B) Average CAT DNA content per embryo after fertilization of injected eggs. The results for both nuclear and cytoplasmic injection samples obtained with the slot blot presented in $\mathrm{A}$ is shown (experiment 1 , $O$, ), together with the results of another experiment, carried out on a separate batch of eggs (experiment 2, $\Delta, \boldsymbol{\Delta}$ ). Also shown in $\mathrm{B}$ is cell number as a function of time after fertilization for cleavage-stage embryos of $L$. variegatus $(---)$. Cell number was determined either by counting individual cells in squashes on slides ( $1 \mathrm{~h}$ intervals from $1-5 h)(\cdot)$, or by reference to the DNA content measured in pooled embryos ( $1 \mathrm{~h}$ intervals from 4-12 h) on the basis that each diploid cell contains $1.6 \mathrm{pg}$ DNA (Pikó et al. 1967) (-). Cell numbers were determined on uninjected control embryos. The cleavage of injected embryos frequently lags by one cycle compared to controls, in consequence of an initial delay prior to the first cleavage. sample and 6/34 in the nuclear sample displayed CAT DNA contents in the range 10-60 times the amount originally injected (compare with Fig. 3). Comparison with our previous $S$. purpuratus results (Flytzanis et al. 1985) suggests that $L$. variegatus embryos may amplify injected DNA slightly less during embryogenesis than do $S$. purpuratus embryos, in which 30 - to $>100$-fold amplification is commonly observed after cytoplasmic injection (McMahon et al. 1985; Flytzanis et al. 1985, 1987), but that in Lytechinus the DNA is apparently more likely to be incorporated in cells that divide during larval growth. This could reflect a difference in cell fate during larval morphogenesis, a subject that is not well explored for any echinoid species. In any case, Fig. $4 \mathrm{~B}$ shows that in the cytoplasmic group $17 / 26$ positive larvae $(65 \%)$ amplified the exogenous DNA $60-$ to $600-$ fold, and only $2(8 \%)$ showed greater amplification. In contrast, in the nuclear injection sample $17 / 34(50 \%)$ fall within the 60 - to 600 -fold amplification class, but $11 / 34$ or $32 \%$ contain more than 700 times the amount of CAT DNA initially introduced into these eggs. Our interpretation is that when introduced directly into the zygote nucleus the exogenous DNA has a significantly greater probability of being included in a vegetal plate lineage or one of the eight small micromere lineages (Pehrson \& Cohen, 1986), which are the predominant sources of the cells from which the imaginal rudiment of the larva is constructed. The rudiment is the major site of extensive cell division during larval morphogenesis. This difference is difficult to detect in the embryo, since most lineages display roughly the same extent of cell replication during embryogenesis, but it becomes obvious after feeding begins, when some lineages reproduce several fold more than do others.

\section{CyIIla. CAT DNA in postmetamorphic juveniles}

The results shown in Fig. 4B imply that a larger fraction of postmetamorphic juveniles raised from eggs in which the exogenous DNA was introduced into the nucleus should retain these sequences than in cytoplasmically injected samples. This follows from the argument that most cell division in the larva occurs in the rudiment from which the juvenile develops. DNA was extracted individually from 58 juveniles of several nuclear injection groups about two months postmetamorphosis, and from 59 juveniles of the corresponding cytoplasmic injection groups (survival and metamorphic success were about the same in the two samples). A sample of each individual DNA was utilized for genome blot hybridization with a labelled CAT DNA probe. These results, together with the frequency of retention of CAT DNA by 2- to 3-week-old larvae (from Fig. 4B), are summarized in Table 1. The fraction of juvenile 


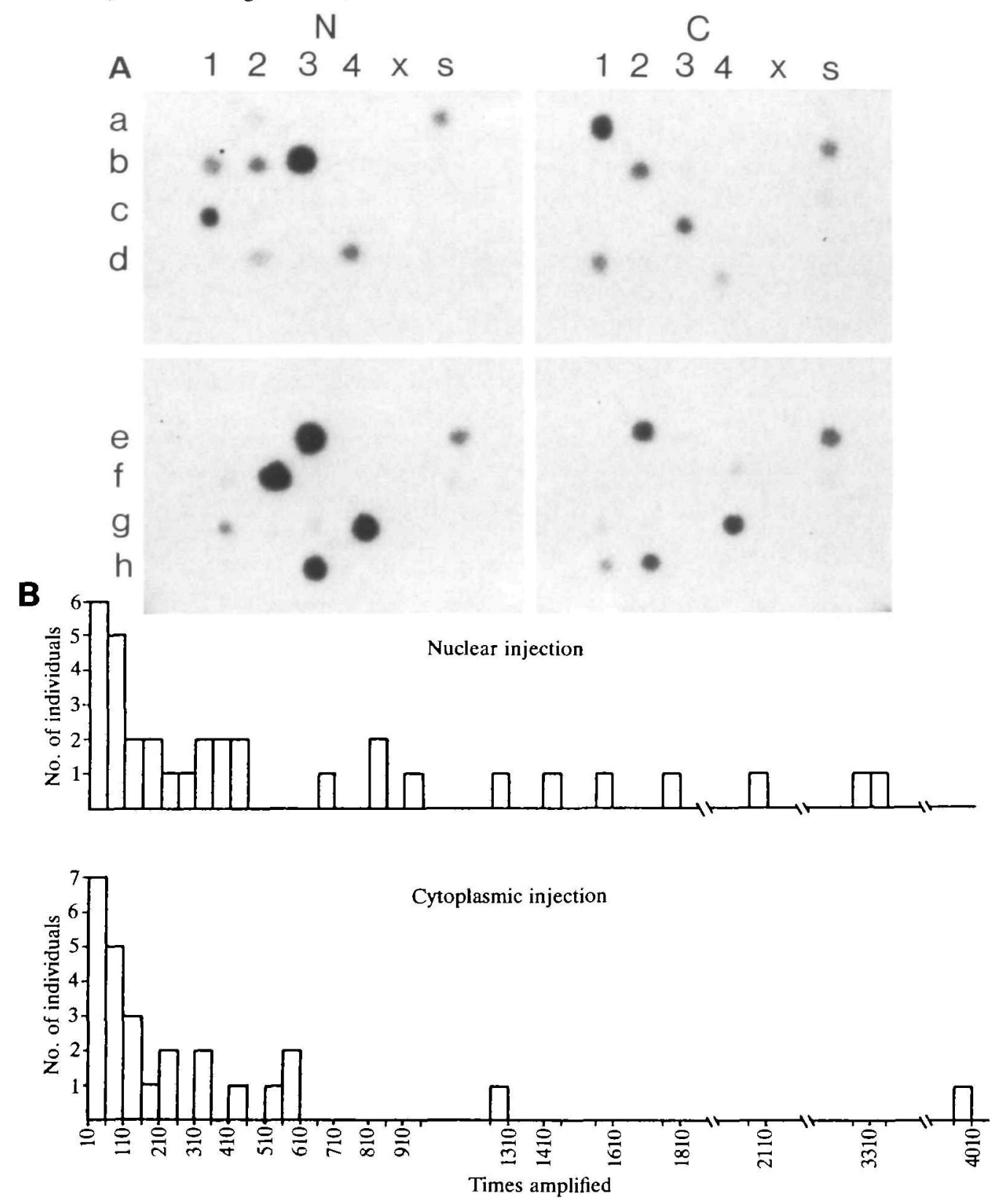

Fig. 4. Exogenous DNA sequences detected by dot-blot hybridization in genomic DNA of advanced feeding larvae. About 3000 molecules of CyIIIa. CAT DNA were microinjected into either the nucleus (N) or cytoplasm (C) of fertilized eggs. (A) Dot-blot hybridizations. Columns 1-4 contained DNA extracted from individual 2- to 3-week larvae raised from the injected eggs. Each position represents an assay carried out on a single larva. DNA extracted from uninjected larvae is in position $x d$ and columns labelled $s$ contain standard quantities of linearized CyIIIa CAT plasmid DNA spotted onto the nitrocellulose filters: sa and se, $9.5 \times 10^{5}$ molecules; sb and sf, $1.9 \times 10^{5}$ molecules; sc and sg, $3.8 \times 10^{4}$ molecules. Two experiments carried out with separate batches of eggs are reproduced: $a-d$ and $e-h$. The filters were hybridized with ${ }^{32} \mathrm{P}$-pSVOCAT probe and autoradiographed. The limit of sensitivity in these experiments was about $4 \times 10^{4}$ CyIIIa. CAT DNA molecules per larva, which would require an approximately 13 -fold amplification of the DNA initially microinjected into the egg. (B) Graphic presentation of exogenous DNA contents in larvae derived from fertilized eggs injected in nucleus or cytoplasm. Estimates were obtained from experiments such as shown in A, by densitometry, with reference to standard amounts of linearized CyIIIa.CAT DNA spotted onto the same filters. Autoradiographic exposure times were adjusted so that the signals obtained for the experimental samples fell within the range of those for the standards and the values obtained were corrected for the relative lengths of exposure. The values shown can be considered minimal due to possible DNA loss during the extractions. The 34 positive larvae included in the nuclear injection histogram represented $53 \%$ of the total individuals assayed and the 26 positive larvae included in the cytoplasmic injection sample were $41 \%$ of the total assayed. Exogenous DNA was not detectable in the remainder (i.e. $<13 \times$ amplification; see A). Results shown are pooled from experiments with two different batches of eggs, which did not differ significantly in their individual distributions. 
Table 1. Exogenous CAT DNA sequences retained in advanced larvae and juveniles

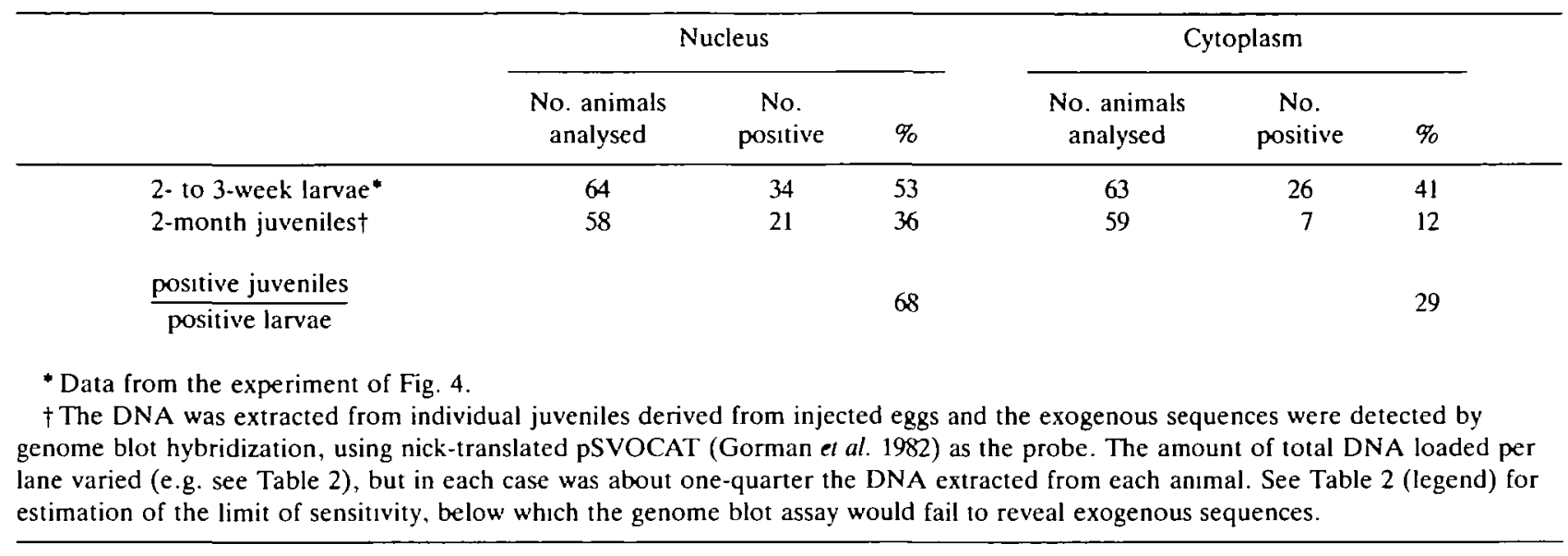

animals displaying CAT DNA in the nuclear injection sample was $36 \%$, i.e. three times the retention frequency in the cytoplasmic injection sample. The juvenile cytoplasmic injection data of Table 1 are consistent with those reported earlier for $S$. purpuratus. Thus Flytzanis et al. (1985) concluded that $5-15 \%$ of postmetamorphic juveniles retain exogenous DNA introduced originally into the cytoplasm of (unfertilized) eggs. Nor in any subsequent trials utilizing cytoplasmic injection have we ever observed a juvenile retention frequency that approaches the $36 \%$ recovery from the nuclear injection sample shown in Table 1. Furthermore, Table 1 indicates that over two thirds of larvae in the nuclear injection group retaining the exogenous DNA would have given rise to juveniles that also retain it. The one third of the larvae in this class that would not have contained exogenous DNA as juveniles must again be considered the consequence of a mosaic exogenous DNA distribution. That is, there are larval lineages, such as the oral ectoderm and ciliary bands, that undergo some replication after feeding begins but that are not included in the rudiment from which the juvenile derives. The degree of mosaicism is clearly higher in the cytoplasmic injection samples, since less than half as many of these positive larvae would give rise on average to positive juveniles (i.e. $29 \%$ versus $68 \%$; Table 1). The results shown in Table 1 support directly the conclusion that nuclear introduction of exogenous DNA results in its stable inclusion in a greater variety of cell lineages, on the average, than does cytoplasmic introduction.

An example of a juvenile genome blot from an animal of the nuclear injection sample is shown in Fig. 5A. The undigested DNA sample (lane U) displays a high-molecular-weight band much longer than the $14 \mathrm{~kb}$ CyIIIa.CAT molecules originally injected. Hybridization of the CAT probe with BglIIdigested DNA (lane D1) reveals two distinct bands of about 20 and $14 \mathrm{~kb}$. As shown in Fig. 5B, these are the reactive fragments expected from $B g l I I$ digestion of a concatenate formed by random end-to-end ligation of Cyllla. CAT DNA linearized at the SphI site. A third fragment of $8 \mathrm{~kb}$ would also be generated upon digestion with $B g / I I$, but since this fragment consists entirely of sea urchin CyIIIa actin sequences it could not react with the CAT DNA probe. Fig. 5 demonstrates that the exogenous DNA concatenate carried in the genome of this particular juvenile is similar in structure to those earlier identified in embryos (McMahon et al. 1985) and juveniles (Flytzanis et al. 1985) developing from cytoplasmically injected $S$. purpuratus eggs. At the resolution of Fig. 5A, most of the CyIIIa. CAT sequences have evidently suffered no major reorganizations or deletions. Some minor bands that could represent junction sequences with the genomic DNA can also be observed in the overexposed autoradiograph displayed in lane D2 (see also Flytzanis et al. 1985). There is an average of at least 54 copies of the CyIIIa. CAT sequence per cell in this juvenile (i.e. if the concatenate were present in every cell). However, as shown in Table 2 , this is a very unusual case. Here measurements of average exogenous DNA content per cell are presented for 11 additional positive juveniles recovered from two zygote nuclear injection series. Of these positive juveniles (out of 18 examined), only the one utilized for the experiment of Fig. 5 contained significantly more than one copy of CAT DNA per cell, on average. Genome blots for most of the remaining positive animals of Table 2 all displayed the same two bands on BgllI digestion as shown in Fig. 5A, indicating that in each case CyIIIa- CAT concatenates were present. We do not know the number $(n)$ of monomers in these low concentration concatenates, and the fractions of cells actually containing CyIIIa.CAT sequences would be 


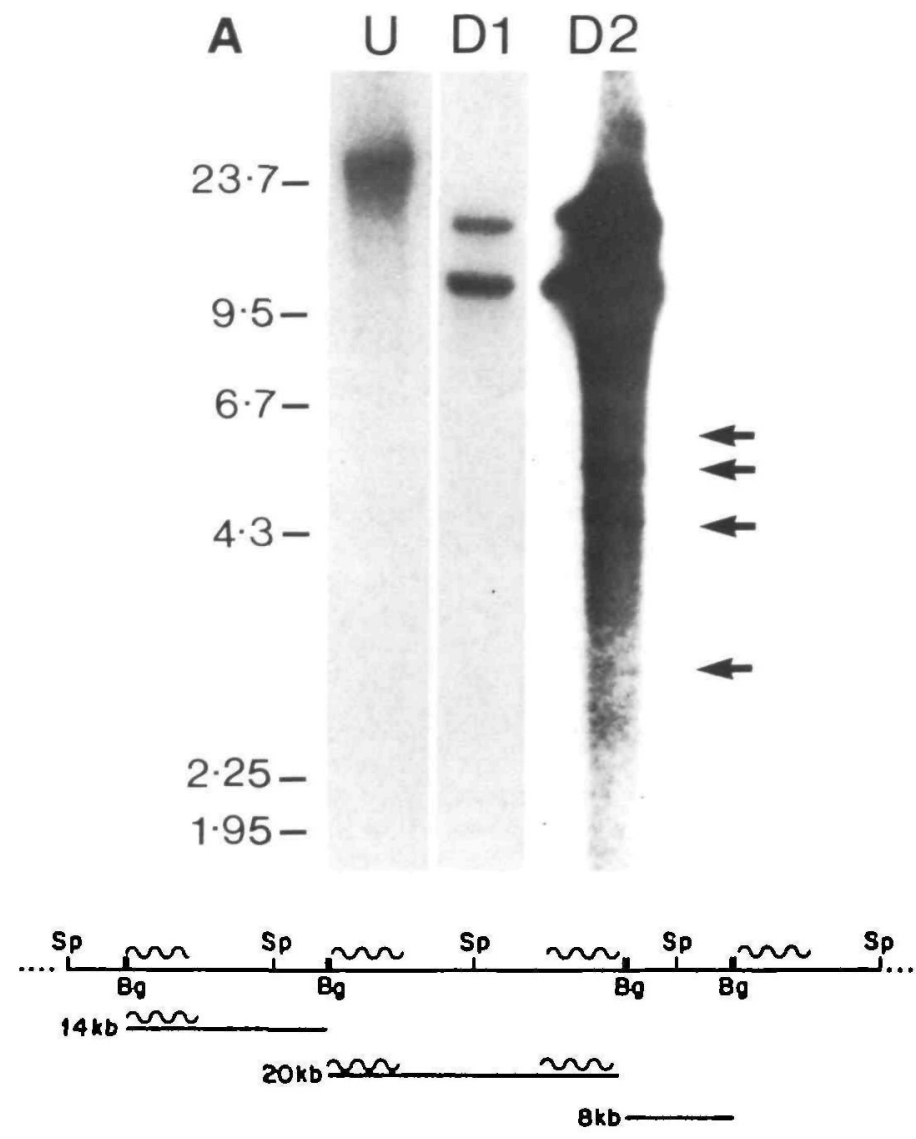

Fig. 5. Concatenated CyIIIa - CAT DNA in a juvenile sea urchin derived from a zygote injected in the nucleus. (A) Genome blot of DNA extracted from a 2-month-old juvenile. About 3000 molecules of CyIIIa CAT were introduced into the nucleus and the individual was reared through metamorphosis. A sample of the DNA was digested with $B g l \mathrm{II}$ and, after electrophoresis, transferred to a nitrocellulose filter (lane D1). Hybridization was performed as described in Materials and methods. The probe was nick-translated pSVOCAT. Arrows indicate the positions in the overexposed autoradiograph (lane D2) of bands that could represent junction sequences between the CAT DNA and genomic DNA. The autoradiograph in lane $U$ shows the hybridization reaction obtained with undigested DNA. (B) Diagram of CyIIIa CAT concatenate that would be formed by random end-to-end ligation of CyIIIa $\cdot$ CAT molecules. The sizes $(\mathrm{kb})$ of the fragments generated by BglII digestion are shown. The wavy line indicates the region of homology between the CyIIIa. CAT sequence and the hybridization probe, pSVOCAT, used for the genome blots.

given by $1 / n \times$ the (CAT DNA/cell) values shown in Table 2 . Thus the proportion of juvenile cells containing the exogenous DNA may in many cases be very small indeed, ranging from $10^{-1}$ to $10^{-4}$ if the concatenates consist of ten monomers, for example. The measurements of Table 2, in sum, provide further direct evidence of the highly mosaic character of exogenous DNA incorporation in the nuclear injection juveniles.

It is very unlikely from the results in Table 2 that zygote nuclear injection could provide a route by which the frequency of incorporation of exogenous DNA into the germ line might be greatly enhanced. Germ line transmission does occur occasionally in animals raised from cytoplasmically injected $S$. purpuratus eggs (Flytzanis et al. 1986). Not surprisingly, examination of $L$. variegatus sperm DNA from eight male sea urchins raised from a zygote nuclear injection series and of the DNA of embryos produced by 15 females from this series yielded no cases in which germ line transmission could be demonstrated.

\section{Discussion}

Stable DNA incorporation following injection of the zygote nucleus or cytoplasm

The measurements presented demonstrate that the nuclear injection procedure does indeed deliver exogenous DNA into the nucleus, as the visual appearance of the injection process would indicate (Fig. 1). Thus, although some of the DNA solution is undoubtedly deposited in the cytoplasm, the results of nuclear injection are easily distinguished from those of cytoplasmic injection. In this study, we utilized eggs of a different species than has previously been employed for DNA transfer, and it is useful to summarize phenomenologically the results from both nuclear and cytoplasmic zygotic injection, as follows. (i) After injection by either route there may occur a lag of several cleavage cycles, and the exogenous DNA then commences to replicate at a rate little different from that of the cellular genomes, so that by termination of cleavage it is present in 10-40 times the mass initially introduced (Fig. 3). Replication in nuclear samples may slightly exceed that in cytoplasmic samples and, in both, a large proportion of the replicated exogenous sequence remains stably incorporated throughout the remainder of embryogenesis. (ii) The majority of individuals in both samples continue to replicate the exogenous DNA during larval growth, but we found that $32 \%$ of advanced larvae derived from nuclear injection zygotes displayed exogenous DNA contents ranging from 700 times to 4000 times the initial inoculum, while all but $8 \%$ of the cytoplasmic injection controls displayed less than 600 times the initial inoculum. (iii) Of postmetamorphic juveniles consisting of $2-8 \times 10^{6}$ cells that were derived from a nuclear injection series, $36 \%$ retained the exogenous DNA sequences versus $12 \%$ for the cytoplasmic injection controls (Table 1 ). (iv) Genome blot hybridizations show that the juveniles retain the injected sequences in a concatenated 
Table 2. Amounts of CyIIIa.CAT DNA in juveniles derived from zygote nuclear injection

\begin{tabular}{|c|c|c|c|c|}
\hline $\begin{array}{l}\text { Individual } \\
\text { juvenile }\end{array}$ & $\begin{array}{l}\text { Amount }(\mu \mathrm{g}) \text { of } \\
\text { total DNA per sample* }\end{array}$ & $\begin{array}{l}\text { No. cells } \\
\text { represented } t\end{array}$ & $\begin{array}{c}\text { Estimated } \\
\text { no. CAT } \\
\text { DNA molecules } \ddagger\end{array}$ & $\frac{\text { CAT DNA molecules } \$}{\text { no. cells represented }}$ \\
\hline 1 & $1 \cdot 3$ & $8.1 \times 10^{5}$ & $4.4 \times 10^{7}$ & $5.4 \times 10^{1}$ \\
\hline 2 & $2 \cdot 2$ & $1.4 \times 10^{6}$ & $1.7 \times 10^{6}$ & $1 \cdot 2$ \\
\hline 3 & 2.9 & $1.8 \times 10^{6}$ & $8.2 \times 10^{5}$ & $5.0 \times 10^{-1}$ \\
\hline 4 & $2 \cdot 0$ & $1.2 \times 10^{6}$ & $2.5 \times 10^{5}$ & $2.0 \times 10^{-1}$ \\
\hline 5 & $2 \cdot 1$ & $1.3 \times 10^{6}$ & $1.8 \times 10^{5}$ & $1.4 \times 10^{-1}$ \\
\hline 6 & $2 \cdot 7$ & $1.7 \times 10^{6}$ & $1.2 \times 10^{5}$ & $1.7 \times 10^{-2}$ \\
\hline 7 & $2 \cdot 6$ & $1.6 \times 10^{6}$ & $8.4 \times 10^{4}$ & $5 \cdot 1 \times 10^{-2}$ \\
\hline 8 & $0 \cdot 8$ & $5.1 \times 10^{5}$ & $1.9 \times 10^{4}$ & $3.8 \times 10^{-2}$ \\
\hline 9 & $2 \cdot 0$ & $1.2 \times 10^{6}$ & $1.1 \times 10^{4}$ & $8.8 \times 10^{-3}$ \\
\hline 10 & $3 \cdot 5$ & $2.2 \times 10^{6}$ & $1.2 \times 10^{4}$ & $5.5 \times 10^{-3}$ \\
\hline 11 & 0.7 & $4.4 \times 10^{5}$ & $<1 \times 10^{4}$ & ND \\
\hline 12 & 1.5 & $9.4 \times 10^{5}$ & $<1 \times 10^{4}$ & ND \\
\hline
\end{tabular}

\footnotetext{
* One quarter of total DNA extracted from each juvenile was utilized per genome blot The amount of total DNA in each sample was estimated as follows. After hybridization with the CAT probe, each blot was washed clean of bound probe (see Materials and methods) and rehybridized with a nick-translated insert derived from pCyI (3'), which includes a single-copy $C y I$ actin gene sequence from the genome of $S$ purpuratus (Lee et al. 1984). This sequence cross-hybridizes with $L$. variegatus genomic DNA. The amount of DNA per sample was calculated by densitometry using as standards the hybridization signals obtaned with known amounts of $L$. variegatus DNA present on the same blot.

$\dagger$ Based on a value of $1.6 \mathrm{pg}$ of DNA per cell (Pik6 et al. 1967)

$\$$ The number of CAT DNA sequences per sample was estimated by densitometry with reference to the hybridization signals obtained with nick-translated pSVOCAT, and standard amounts of linearized CyIIIa . CAT DNA placed on the same filter. The lımıt of sensitivity in these experiments was about $1 \times 10^{4}$ plasmid molecules, with hybridization signals below this value too weak to measure by densitometry.

8 Estimated no. of CAT DNA molecules (column 4)

No. of cells represented (column 3 )

For samples containing less DNA the mınımum value for this ratio that could have been detected would of course be proportionately higher.

I ND, Could not be determined, due to amounts of CAT DNA too low for reliable densitometric estimation. Out of a similar-sized cytoplasmic injection sample (1.e. 18 individuals) examined at the same time only two were positive, and both contained quantities of CAT DNA below the limits of these measurements.
}

form (Fig. 5), but in most animals they are present in only small fractions of cells, perhaps in clones of the order of only $10^{2}$ cells in some cases, much more in others (Table 2). The previous demonstrations of Flytzanis et al. (1985) in $S$. purpuratus show that the exogenous DNA is integrated into the genome in postlarval juveniles, and this may possibly occur as early as the onset of replication in cleavage.

\section{Interpretation: a mosaic pattern of exogenous DNA incorporation following nuclear injection}

As argued in detail above, all the results reported can be explained by the proposition that the predominant result of direct introduction of exogenous DNA into the zygote nucleus is the stable association of the DNA with the replicating chromosomes of a subset of embryonic cell nuclei several cleavage cycles later. The replication kinetics suggest that this is likely to have occurred in both nuclear and cytoplasmic samples during cleavage, and no doubt earlier in some embryos of each sample, and later in others. A large fraction of the progeny of the eight vegetal half blastomeres in the 4th cleavage embryo will contribute significantly to the imaginal rudiment of the larva, while only a very small fraction of the ectodermal structures derived from the animal half gives rise to rudiment components (reviewed by Hyman, 1955; Cameron \& Hinegardner, 1974; Davidson, 1986; Cameron et al. 1987). To all intents and purposes, the rudiment precursors amount to about half the blastomeres of the 3 rd or 4 th cleavage embryo. Later this fraction declines, due to the mitotic quiescence throughout embryogenesis of the eight small micromeres (Pehrson \& Cohen, 1986). In larvae displaying very extensive exogenous DNA replication, these sequences must be included in the rudiment, which ultimately contains the large majority of the larval cells. Thus, if, for example, in two thirds of the positive individuals in a zygote nuclear injection sample incorporation occurred randomly in a single 3rd or 4th cleavage blastomere, one half of these embryos, i.e. one third of the total, just as observed (Fig. 4B; Table 1), would produce larvae in which the rudiments contained the injected sequences and from which would derive juveniles carrying these sequences. In the remainder, incorporation might occur later than 4th cleavage, decreasing in these embryos 
the frequency with which the exogenous DNA will be included in the rudiment. However, there is another factor particular to the case of cytoplasmic injection that is worth considering as well. This is that the eight small micromeres, which may contribute significantly to the rudiment (Pehrson \& Cohen, 1986), might often be excluded from the distribution of injected DNA, which is normally placed toward the middle of the egg. In any case, Hough-Evans and Davidson (unpublished data) have found in cytoplasmically injected $S$. purpuratus eggs the distribution of the fractions of cells containing the exogenous DNA centres symmetrically around 5-9\%, suggesting a maximum frequency of stable incorporation of exogenous DNA at 4th cleavage. These data also suggest that in some embryos the DNA must be incorporated as early as 3rd cleavage and, in others, as late as 6th cleavage. Since about half the cells of the 3rd-4th cleavage embryo contribute some progeny to the rudiment structures of the larva, a significant bias against inclusion in the polar small micromeres seems the most likely explanation for the low frequency $(\sim 1 / 12$ th $)$ of larvae descendant from cytoplasmically injected eggs that contain the exogenous DNA in the rudiment. That is, if no small micromeres were to receive this DNA, the expected fraction of larvae whose rudiments contain exogenous DNA would be $1 / 8$ for embryos in which incorporation occurred at 3 rd cleavage, and $1 / 16$ or less for those in which incorporation occurred later. Since in this model stable exogenous DNA incorporation occurs at about the same stage, i.e. 4th cleavage, on average, irrespective of the route of DNA introduction, little detectable difference would be expected in the overall exogenous DNA contents of the nuclear versus cytoplasmic injection samples at the end of cleavage, just as observed, particularly since the eight small micromeres cease division at 6 th cleavage. On the other hand, it provides an interpretation of the large statistical distinction we report for the larval and postmetamorphic juvenile stages, i.e. the three- and fourfold increases, respectively, in the fractions retaining exogenous DNA after nuclear injection.

Mosaic incorporation in the nuclear injection sample is directly shown by the genome blot measurements of Table 2, and by the results of Table 1 as well. Thus the emergence of the juvenile from the larva is in fact itself a process of cell lineage segregation, in that most products of the oral and the aboral ectoderm lineages are left behind. Table 1 shows that in $71 \%$ of the positive larvae in the cytoplasmic injection sample the exogenous DNA is confined to such specifically larval lineages, versus only $32 \%$ in the nuclear injection sample. While direct proof of the mosaic incorporation scenario here invoked would require for the nuclear injection sample a developmental series of DNA in situ hybridizations, there seems no plausible alternative, particularly since mosaic incorporation has already been demonstrated by this (unpublished data) and other methods (Flytzanis et al. 1985, 1987) to occur following cytoplasmic injection. One variant is that in nuclear injection samples the DNA could be initially incorporated in all or most nuclei and then lost from a majority during embryonic development. While some decrease in exogenous DNA content does occur (Fig. 3), possibly due to recombinational deletions from the tandem concatenates in which the DNA is initially organized (McMahon et al. 1985), the observed loss occurs equally in both nuclear and cytoplasmic samples. In addition, this mechanism would imply a much greater initial replication in the nuclear injection sample, which is not observed.

\section{Potential advantages of zygotic nuclear DNA injection}

There are at least two important experimental opportunities suggested by these observations. Expression studies on genes that function in only a few cells, or late in development, or in the rudiment itself, will be greatly facilitated by use of a system that increases the probability of inclusion of the exogenous gene in the cell type of interest. This is probably the most important and immediate practical advantage of the nuclear introduction system we describe. A second, more long-range, possibility is to exploit the mosaic incorporation feature by using it to study cell lineage in the morphogenesis of the imaginal rudiment itself, a problem of great fascination which at present is almost inaccessible. Unlike the embryo, the sea urchin larval rudiment develops from mesenchymal and other cells that cannot directly utilize the preformed three-dimensional spatial coordinates which the embryo inherits from the egg. The process by which rudiment progenitor cells sort out and establish their own spatial coordinates may in many ways resemble that by which pattern formation is initiated from totipotent cells in the postimplantation mammalian embryo. Injection of a suitable reporter gene into the zygote nucleus, the products of which can be detected cytologically (e.g. de Wet et al. 1987), could provide a series of clonal rudiment lineage markers that could be used to identify the origins and fates of small sets of cells as differentiation and multicellular organization take place in the rudiment. The advantage of such a marker is, of course, that it would not be abolished by dilution in consequence of extensive cell multiplication as are the 'passive' lineage markers now in use.

It is our pleasure to acknowledge $\operatorname{Dr} \mathrm{R}$. Andrew Cameron for cell number determinations in squashed preparations of early embryos, Mr Patrick Leahy for 
culturing sea urchin embryos, larvae and juveniles and $\mathrm{Mr}$ Jeffrey Tekanic for his help with genome blot assays. This research was supported by NIH grant HD-05753. R.R.F. was supported by an NIH Postdoctoral Training Grant HD-07257.

\section{References}

Akhurst, R. J., Calzone, F. J., Lee, J. J., Brttten, R. J. \& Davidson, E. H. (1987). Structure and organization of the Cylll actin gene subfamily of the sea urchin, Strongylocentrotus purpuratus. J. molec. Biol. 194, 193-203.

Brunk, C. F., Jones, K. C. \& James, T. W. (1979). Assay for nanogram quantities of DNA in cellular homogenates. Analyt. Biochem. 92, 497-500.

Cameron, R. A. \& Hinegardner, R. T. (1974). Initiation of metamorphosis in laboratory-cultured sea urchins. Biol. Bull. mar. biol. Lab., Woods Hole 146, 335-342.

Cameron, R. A., Hough-Evans, B. R., Britten, R. J. \& Davidson, E. H. (1987). Lineage and fate of each blastomere of the eight-cell sea urchin embryo. Genes \& Dev. 1, 75-84.

Colin, A. M., Catlin, T. L., Kidson, S. H. \& Maxson, R. (1987). Closely linked early and late H2b histone genes are differentially expressed after microinjection into sea urchin zygotes. Proc. natn. Acad. Sci. U.S.A. (in press).

Davidson, E. H. (1986). Gene Activity in Early Development, 3rd edn. Orlando: Academic Press.

Davidson, E. H., Flytzanis, C. N., Lee, J. J., Robinson, J. J., Rose, S. J., III \& Sucov, H. M. (1985). Lineage-specific gene expression in the sea urchin embryo. Cold Spring Harbor Symp. quant. Biol. 50, 321-328.

De Wet, J. R., Wood, K. V., Deluca, M., Helsinki, D. R. \& Subramani, S. (1987). Firefly luciferase gene: Structure and expression in mammalian cells. Mol. cell. Biol. 7, 725-737.

Flytzanis, C. N., Britten, R. J. \& Davidson, E. H. (1987). Ontogenic activation of a fusion gene introduced into the sea urchin egg. Proc. natn. Acad. Sci. U.S.A. 84, 151-155.

Flytzanis, C. N., McMahon, A. P., Hough-Evans, B. R., Katula, K. S., Britten, R. J. \& Daví́son, E. H. (1985). Persistence and integration of cloned DNA in postembryonic sea urchins. Devl Biol. 108, 431-442.

Forbes, D. J., Kirschner, M. W. \& Newport, J. W. (1983). Spontaneous formation of nucleus-like structures around bacteriophage DNA microinjected into Xenopus eggs. Cell 34, 13-23.
Franks, R. R., Hough-Evans, B. R., Britten, R. J. \& Davidson, E. H. (1988). Spatially deranged but temporally correct expression of a sea urchin actin gene in transgenic embryos of a different genus. Genes \& Dev. (in press).

Gorman, C. M., Moffat, L. F. \& Howard, B. H. (1982). Recombinant genomes which express chloramphenicol acteyltransferase in mammalian cells Mol. cell. Biol. 2, 1044-1051

Hinegardner, R. T. \& Rocha Tuzzi, M. M. (1981). Laboratory culture of the sea urchin Lytechinus pictus. In Marine Invertebrates, pp. 291-302. Washington, DC: National Academy Press.

Hough-Evans, B. R., Franks, R. R., Cameron, R. A., Britten, R. J. \& Davidson, E. H. (1987). Correct cel type-specific expression of a fusion gene injected into sea urchin eggs. Devl Biol. 121, 576-579.

Hyman, L. H. (1955). The Invertebrates: Echinodermata. The Coelomate Bilateria, vol. IV. New York: McGrawHill.

Katula, K. S., Hough-Evans, B. R., Britten, R. J. \& Davidson, E. H. (1987). Ontogenic expression of a CyI actin fusion gene injected into sea urchin eggs. Development 101, 437-447.

LEAHY, P. S. (1986). Laboratory culture of Strongylocentrotus purpuratus adults, embryos, and larvae. Meth. Cell Biol. 27, 1-13.

Lee, J. J., Shott, R. J., Rose, S. J. III, Thomas, T. L., Britten, R. J. \& Davidson, E. H. (1984). Sea urchin actin gene subtypes: Gene number, linkage, and evolution. J. molec. Biol. 172, 149-176.

McMahon, A. P., Flytzanis, C. N., Hough-Evans, B. R., Katula, K. S., Britten, R. J. \& Davidson, E. H (1985). Introduction of cloned DNA into sea urchin cytoplasm: Replication and persistence during embryogenesis. Devl Bıol. 108, 420-430.

McMahon, A. P., Novak, T. J., Britten, R. J. \& Davidson, E. H. (1984). Inducible expression of a cloned heat shock fusion gene in sea urchin embryos. Proc. natn. Acad. Sci. U.S.A. 81, 7490-7494.

Pehron, J. R. \& Cohen, L. H. (1986). The fate of the small micromeres in sea urchin development. Devl Biol. 113, 522-526.

Pikó, L., Tyler, A. \& Vinograd, J. (1967). Amount, location, priming capacity, circularity and other properties of cytoplasmic DNA in sea urchin eggs. Biol. Bull. mar. biol. Lab., Woods Hole 132, 68-90.

Schatten, G. (1982). Motility during fertilization. Int. Rev. Cytol. 79, 59-164.

Southern, E. M. (1975). Detection of specific sequences among DNA fragments separated by gel electrophoresis. J. molec. Biol. 98, 503-517.

(Accepted 4 November 1987) 
